\title{
PEMBINAAN DAN IMPLEMENTASI MANAJEMEN KEUANGAN SEBAGAI PERSIAPAN MEMASUKI JENJANG PERGURUAN TINGGI, DUNIA KERJA DAN WIRAUSAHA SISWA DAN SISWI SMK MUHAMMADIYAH PARUNG
}

\author{
${ }^{1}$ Widya Intan Sari, ${ }^{2}$ Rizka Wahyuni Amelia, ${ }^{3}$ Mitri Nelsi, ${ }^{4}$ Arif Hidayat, \\ ${ }^{5}$ Asep Muhammad Lutfi, ${ }^{6}$ Moh.Alfatur Rozi, ${ }^{7}$ Annisa Maharani, \\ ${ }^{8}$ Fuad Abi Hanif \\ 1,2,3,4,5 Dosen Fakultas Ekonomi Universitas Pamulang \\ ${ }^{6,7,8}$ Mahasiswa Program Studi Manajemen Universitas Pamulang \\ Email : 1 intansvp@gmail.com
}

\begin{abstract}
ABSTRAK
Tujuan kegiatan ini adalah untuk melakukan pembinaan dan implementasi manajemen keuangan sebagai persiapan memasuki jenjang perguruan tinggi, dunia kerja dan wirausaha siswa dan siswi SMK Muhammadiyah Parung

Metode pelaksanaan adalah dengan memberikan pelatihan, memberikan implementasi manajemen keuangan, memberikan gambaran tentang jenjang perguruan tinggi; dunia kerja dan wirausaha serta memberikan siswa dan siswi pelatihan membuat rencana keuangan pribadi.

Ketercapaian target materi pada kegiatan PKM ini cukup baik, karena materi pembinaan dan implementasi manajemen keuangan sebagai persiapan menuju jenjang yang lebih tinggi yaitu perguruan tinggi, dunia kerja dan wirausaha telah dapat disampaikan secara keseluruhan. Secara keseluruhan kegiatan pembinaan dan implementasi manajemen keuangan sebagai persiapan menuju jenjang yang lebih tinggi yaitu perguruan tinggi, dunia kerja dan wirausaha untuk bekal siswa/siswi nantinya ketika mereka sudah berhasil lulus.
\end{abstract}

\section{Kata Kunci : Pembinaan dan Implementasi, Manajemen Keuangan}

\section{PENDAHULUAN}

Lembaga pendidikan dari semua jenjang pendidikan merupakan organisasi yang dalam operasinya membutuhkan uang untuk menggerakkan sumber daya yang dimilikinya (A. Rusdiana, 2013). Suatu lembaga pendidikan untuk memiliki reputasi yang bagus dan label prestasi juga harus bisa dengan baik mengelola sumber daya uang yang ada. Karena itu, mengingat bahwa pengelolaan sumber daya uang baik oleh lembaga pendidikan maupun pengelolaan pribadi diperlukan, setiap siswa khususnya siswa SMA atau SMK yang ingin melanjutkan ke jenjang pendidikan yang lebih tinggi yaitu jenjang perguruan tinggi, diperlukan pengelolaan manajemen keuangan yang baik sebelumnya. Permasalahan yang ada di SMK Muhammadiyah Parung adalah siswa dan siswi menyadari kurangnya pengetahuan bagaimana cara mengelola keuangan atau memanajemen keuangan 
dalam perisiapan menuju jenjang perguruan tinggi, dunia kerja bahkan berwirausaha.

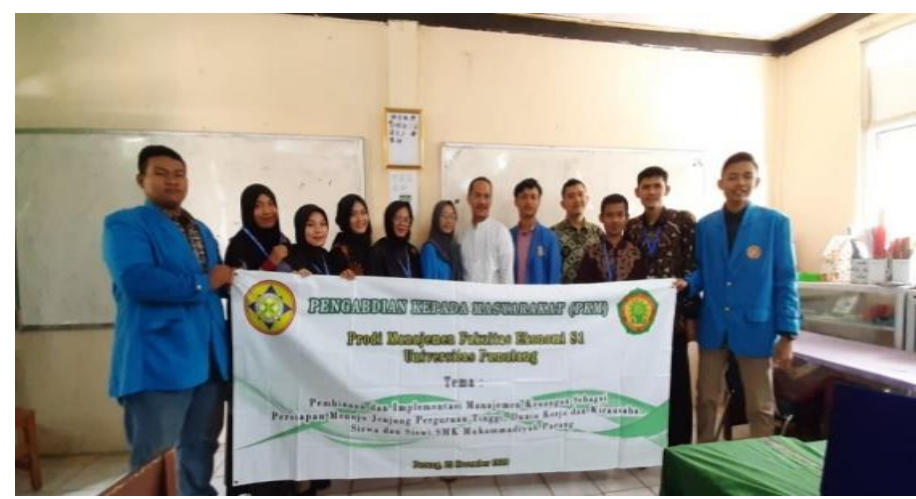

Gambar 1. Foto Bersama dengan Kepala Sekolah

SMK Muhammadiyah Parung merupakan Sekolah Menengah Kejuruan Swasta yang terletak di Jl. H. Mawi No.292, Kelurahan Bojong Indah, Kecamatan Parung, Bogor, Jawa Barat. Sejarah Singkat SMK Muhammadiyah Parung:Berdirinya SMK Muhammadiyah Parung adalah perwujudan dari keinginan warga Muhammadiyah dan simpatisan yang berada di Parung dan sekitarnya dalam upaya mencerdaskan kehidupan bangsa dan mengembangkan manusia-manusia Indonesia seutuhnya, yaitu manusia yang beriman dan bertakwa kepada Allah Swt., berbudi pekerti luhur, memiliki pengetahuan dan keterampilan, sehat jasmani dan rohani, berkepribadian yang mantap dan mandiri serta rasa tanggungjawab kemasyarakatandan kebangsaan.Persyarikatan Muhammadiyah di Parung persisnya di Desa Bojong Indah (dulu Bojong Sempu) telah ada sejak pertengahan tahun 70-an, dan telah memiliki amal usaha seperti : TK ABA ('Aisyiyah Busthanul Athfal) 77, SD Muhammadiyah 58 Ciseeng, SMP Muhammadiyah 37 Parung dan SMA Muhammadiyah Parung.

Didirikanlah SMK Muhammadiyah Parung yang berkedudukan di Jalan H. Mawi No. 292 Desa Bojong Indah, Kec. Parung Kab. Bogor Kode Pos 16330.Selanjutnya oleh Pimpinan Cabang Muhammadiyah Ciputat para pemrakarsa di atas dikukuhkan sebagai pendiri SMK Muhammadiyah Parung berdasarkan surat No. II.A/2-a/163/2000 tanggal 20 Oktober 2000. Dan sekarang untuk pengelolaan SMK Muhammadiyah Parung diserahkan kepada Pimpinan Cabang Muhammadiyah Parung.

Kami memilih SMK Muhammadiyah Parung karena salah satu teman sejawat kami yaitu Dosen di Universitas menjadi Tenaga Pengajar di SMK tersebut dan menyatakan bahwa siswa dan siswi di SMK tersebut memiliki keterbatasan pengetahuan atau kurangnya pengetahuan bagaimana cara mengelola keuangan atau memanajemen keuangan dalam persiapan menuju jenjang yang lebih tinggi yaitu Perguruan tinggi, Dunia kerja dan Wirausaha dan Pihak Sekolah SMK Muhammadiyah Parung bersedia menyediakan tempat dan sarana untuk terlaksananya Program Pengabdian Kepada Masyarakat di tempat tersebut. Kami 
merasa sangat perlu membagikan ilmu yang kami punya tentang bagaimana Memanajemen keuangan sebagai persiapan ke jenjang yang lebih tinggi seperti Perguruan tinggi, dunia kerja dan wirausaha, karena kami merupakan lulusan Master manajemen yang berbasic keuangan dan kami mengajar mata kuliah keuangan di Universitas Pamulang.

\section{METODE PELAKSANAAN KEGIATAN}

Pelatihan pembuatan barang kerajinan tangan ini dibagi dalam 2 metode besar. Kedua metode tersebut adalah metode pra-pelatihan dan metode pelaksanaan kegiatan pelatihan.

Metode pra-pelatihan berisi kegiatan antara lain pengumpulan barang bekas, penyimpanan, penyortiran dan pembersihan barang bekas air mineral. Kegiatan dalam bagian ini membutuhkan waktu kurang lebih dua hingga tiga bulan.

Kegiatan pelatihan berisi antara lain ceramah, peragaan, praktek dan tanya jawab. Kegiatan ini membutuhkan waktu 6 hari yang dilakukan di akhir bulan Juni dan awal Juli 2019 pada saat libut anak sekolah. Dilakukan pada libur anak sekolah pada akhir Juni dan awal Juli karena kegiatan ini ditargetkan anak-anak usia sekolah dari SD kelas 4 hingga SMU kelas 2 yang mengikuti kegiatan pelatihan ini.

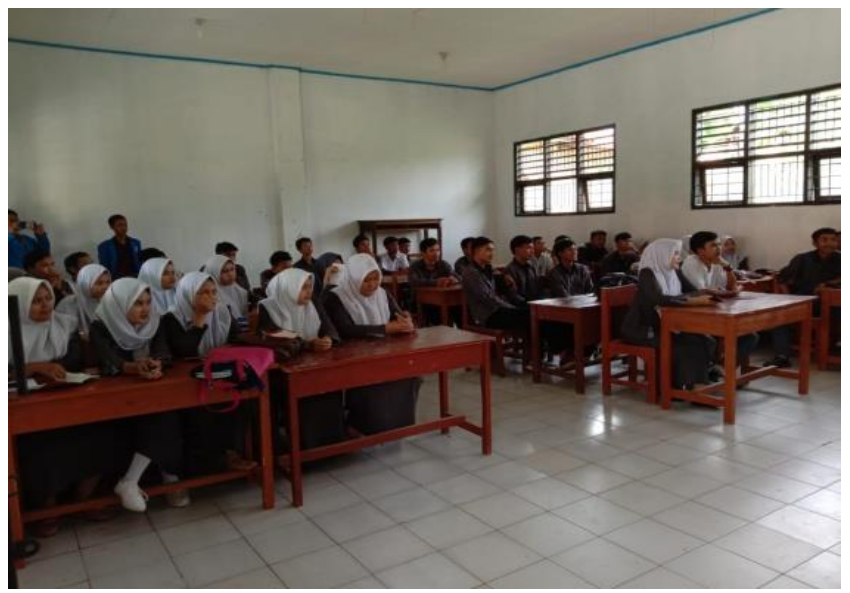

Gambar 2. Sosialisasi Terhadap Siswa Sisiwi SMK Muhammadiyah Parung

\section{HASIL DAN PEMBAHASAN}

Hasil kegiatan PKM secara garis besar mencakup beberapa komponen sebagai berikut: 1. Keberhasilan target jumlah peserta pembinaan 2. Ketercapaian tujuan pembinaan 3. Ketercapaian target materi yang telah direncanakan 4 . Kemampuan peserta dalam penguasaan materi pembinaan dan implementasi manajemen keuangan sebagai persiapan menuju jenjang yang lebih tinggi yaitu perguruan tinggi, dunia kerja dan wirausaha seperti direncanakan sebelumnya adalah paling tidak 31siswa/siswi di SMK Muhammadiyah Parung. Dengan demikian dapat dikatakan bahwa target peserta tercapai 100\%. Angka tersebut menunjukkan bahwa kegiatan PKM dilihat dari jumlah peserta yang mengikuti dapat dikatakan berhasil/ sukses. Ketercapaian tujuan pembinaan dan implementasi 
manajemen keuangan sebagai persiapan menuju jenjang yang lebih tinggi yaitu perguruan tinggi, dunia kerja dan wirausaha secara umum sudah baik, maka dapat disimpulkan bahwa tujuan kegiatan ini dapat tercapai. Ketercapaian target materi pada kegiatan PKM ini cukup baik, karena materi pembinaan dan implementasi manajemen keuangan sebagai persiapan menuju jenjang yang lebih tinggi yaitu perguruan tinggi, dunia kerja dan wirausaha telah dapat disampaikan secara keseluruhan. Secara keseluruhan kegiatan pembinaan dan implementasi manajemen keuangan sebagai persiapan menuju jenjang yang lebih tinggi yaitu perguruan tinggi, dunia kerja dan wirausaha untuk bekal siswa/siswi nantinya ketika mereka sudah berhasil lulus.

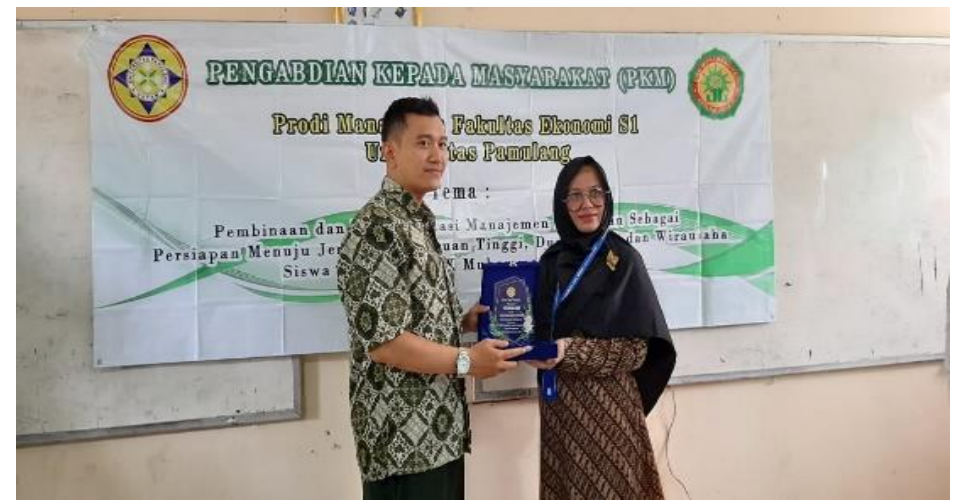

Gambar 3. Simbolis Pemberian Plakat Kepada Pihak SMK Muhammadiyah Parung

\section{KESIMPULAN DAN SARAN}

Program pengabdian pada masyarakat berupa pembinaan dan implementasi manajemen keuangan sebagai persiapan menuju jenjang yang lebih tinggi yaitu perguruan tinggi, dunia kerja dan wirausaha dapat diselenggarakan dengan baik dan berjalan dengan lancar sesuai dengan rencana kegiatan yang telah disusun. Kegiatan ini mendapat sambutan sangat baik terbukti dengan keaktifan peserta mengikuti pendampingan dengan tidak meninggalkan tempat sebelum waktu pembinaan dan implementasi berakhir.

Disarankan bahwa berdasarkan evaluasi yang telah dilakukan dapat diajukan beberapa saran sebagai berikut: 1). Waktu pelaksanaan kegiatan pengabdian perlu ditambah agar tujuan kegiatan dapat tercapai sepenuhnya, tetapi dengan konsekuensi penambahan biaya pelaksanaan. Oleh karena itu biaya PKM sebaiknya tidak sama antara beberapa tim pengusul proposal, mengingat khalayak sasaran yang berbeda pula. 2). Adanya kegiatan lanjutan yang berupa pelatihan sejenis selalu diselenggarakan secara periodik sehinga dapat meningkatkan pengetahuan dan kemampuan siswa/siswi dalam persiapan menuju jenjang yang lebih tinggi 
DAFTAR PUSTAKA

A Sobarna, S Hambali, S Sutiswo, D Sunarsi. (2020). The influence learning used $\mathrm{ABC}$ run exercise on the sprint capabilities. Jurnal Konseling dan Pendidikan 8 (2), 67-71

A Sudarsono, D Sunarsi. (2020). Pengaruh Kualitas Pelayanan Dan Varian Produk Terhadap Keputusan Pembelian Pada Laboratorium Klinik Kimia FarmaBintaro. Value: Jurnal Manajemen dan Akuntansi 15 (1), 16-26

D Prasada, S Sarwani, M Catio. (2019). Pengaruh Kompensasi Dan Lingkungan Kerja Terhadap Kinerja Karyawan Pada PT. Mitra Adiperkasa, Tbk. Jurnal Manajemen, Bisnis dan Organisasi (JUMBO) 3 (3), 195-20765.

D Sunarsi. (2014). Pengaruh Gaya Kepemimpinan, Motivasi dan Disiplin Kerja Terhadap Kinerja Pendidik. Universitas Pamulang

D Sunarsi. (2014). Pengaruh Gaya Kepemimpinan, Motivasi dan Disiplin Kerja Terhadap Kinerja Pendidik. Universitas Pamulang

Gumilar, I., Sunarsi, D. (2020). Comparison of financial performance in banking with high car and low car (Study of banks approved in the kompas 100 index for the period 2013-2017). International Journal of Psychosocial Rehabilitation. Volume 24 - Issue 7

Guntur Setiawan. 2004. "Impelemtasi dalam Birokrasi Pembangunan". Balai Pustaka. Jakarta.

Maddinsyah, A., Sunarsi, D., Hermawati, R., Pranoto. (2020). Analysis of location selection effect on the user decision that influcence the success of the service business of micro, small and medium enterprise (MSME) in bandung timur region. International Journal of Advanced Science and Technology. Vol. 29 No. 06

Nurdin Usman. 2002. “Konteks Implementasi Berbasis Kurikulum”. Grasindo. Jakarta.

Purwanti, P., Sarwani, S., \& Sunarsi, D. (2020). Pengaruh Inovasi Produk Dan Brand Awareness Terhadap Keputusan Pembelian Konsumen Pada Pt. Unilever Indonesia. Inovasi, 7(1), 24-31.

Sunarsi, D., \& Asmalah, L. (2018). Pelatihan Manajemen Pengembangan Diri Bagi Penerima Beasiswa RZIS UGM Dan Dompet Shalahuddin Jogjakarta. Jurnal Pengabdian Dharma Laksana, 1(1), 51-60.

Sunarsi, D., \& Erlangga, A. (2020). The Effect of Leadership Style and Work Environment on the Performance of Stationary Pump Operators in the Water Resources Office of West Jakarta City Administration. International Journal of Advances in Social and Economics, 2(3).

Sunarsi, D., Kustini, E., Lutfi, A. M., Fauzi, R. D., \& Noryani, N. (2019). Penyuluhan Wirausaha Home Industry Untuk Meningkatkan Ekonomi Keluarga Dengan Daur Ulang Barang Bekas. BAKTIMAS: Jurnal Pengabdian pada Masyarakat, 1(4), 188-193.

Sunarsi, D., Kusjono, G., \& Nuryana, I. (2019). Pelatihan Manajemen Penguasaan Kelas Dan Pembuatan Bahan Ajar Bagi Tenaga Pengajar Sukarela Taman Belajar Kreatif Mekarsari. Jurnal Pengabdian Dharma Laksana, 2(1), 41-44. 